\title{
A DIVERGÊNCIA ENTRE CHINA E BRASIL NA QUESTÃO DA IMIGRAÇÃO: NEGOCIAÇÕES DIPLOMÁTICAS EM PARIS DURANTE A MISSÃO ESPECIAL À CHINA (1893)
}

\section{THE DIVERGENCE BETWEEN CHINA AND BRAZIL ON CHINESE IMMIGRATION: DIPLOMATIC NEGOTIATIONS IN PARIS DURING THE SPECIAL MISSION TO CHINA (1893)}

Jinxu Wang*

RESUMO: Em março do 1893, uma Missão Especial foi constituída e enviada para China, com intuito de resolver os problemas da escassez de mão-de-obra na economia brasileira, negociando a imigração chinesa ao Brasil. A preparação iniciou-se em fevereiro de 1892, quando Gabriel Piza, então ministro do Brasil em Paris, e Tching Tchang, conselheiro da Legação Chinesa em Paris, negociaram sobre o despacho desta Missão. O Barão de Ladário, o almirante da marinha, José Costa de Azevedo, foi nomeado o representante extraordinário e ministro plenipotenciário da Missão, também realizou encontros de negociação com Tching Tchang durante sua estadia em Paris. O presente artigo aborda os resultados das negociações e seus impactos sobre o projeto brasileiro para a imigração chinesa. Este trabalho baseia-se nos arquivos de Tsung-Li Yamên (autoridade que tratou assuntos exteriores no governo chinês da época) e o relatório entregue ao Itamaraty pelo Barão de Ladário.

Palavras-chave: História da China. História das Relações Diplomáticas entre Brasil e China. Imigração chinesa.

Abstract: In March 1893, in order to solve the problem of labor shortage in Brazil, a Special Mission was organized and sent to China, to negotiate Chinese immigration to Brazil. The preparation of this negotiation began in February 1892, when Gabriel Piza, the minister of Brazil in Paris, and Tching Tchang, the Chinese diplomate of the Chinese Legation in Paris, held talks on the dispatch of the Mission

*Jinxu Wang, aluna doutorando do programa de PPG-Letras na Universidade de São Paulo, São Paulo, SP, Brasil. OrciD: 0000-0001-8477-1301.

Email: <wang_jinxu@outlook.com>. 
from Brazil. In the end of 1892, Baran of Ladário (José Costa de Azevedo) was nominated extraordinary and plenipotentiary minister of the Mission. In Paris, the Baran also held meetings with Tching Tchang, and drafted a memorandum about the free migration of Chinese labor to Brazil. This article addresses the results of the negotiations and specifically the impact of the negotiations on the fate of the Mission. This paper uses the archival sources of Tsung-Li Yamên (The Qing government ministry specialized in dealing with foreign affairs) and the report delivered to Itamaraty by José da Costa Azevedo, allowing us to understand the different views about the same event.

Keywords: History of China. History of sino-Brazilian Diplomatic relations. Chinese immigration to Brazil.

\section{Introdução $^{1}$}

No dia 5 de outubro de 1892, a lei $\mathrm{n}^{\circ} 97$ permitiu a livre entrada de imigrantes asiáticos (principalmente chineses e japoneses) no Brasil, o recém-formado governo republicano decidiu, de acordo com esta mesma legislação, implementar o Tratado de Amizade, Comércio e Navegação assinado com a China em 1880, enviando agentes diplomáticos a China, em prol do motivo destacado de promover a imigração chinesa ao Brasil ${ }^{2}$. Seguindo a orientação do governo brasileiro, Gabriel de Toledo Piza e Almeida, ministro do Brasil em Paris, enviou uma nota a Xue Fu-cheng, embaixador da China a Inglaterra, França, Bélgica, e Itália, no dia 25 de outubro de 1892, dizendo que o Ministério dos Negócios Estrangeiros do Brasil, em nome do presidente, "expressou a vontade de restabelecer representações diplomáticas em Pequim” para "manter a amizade" conselheiro baseado em Paris, conduzisse os negócios com o Brasil. Neste contexto, a

\footnotetext{
${ }^{1}$ Quero agradecer a Sthefany por sua ajuda na revisão deste artigo. E afirmo que ela não é responsável pelos erros e limitações do texto.

${ }^{2}$ BRASIL, 1892

3 TSUNG-LI YAMÊN, 2020, 01-15-047-06-006. Notas: os manuscritos de TSUNG-LI YAMÊN foram fotocopiados e arquivados em data-base interno, codificados por 12 dígitos equivalentes à ordem numérica de páginas. Assim coloca-se o código do documento na posição da página da citação.
} 
negociação entre Tching Tchang e Gabriel Piza foi realizada em Paris, principalmente sobre o envio de uma missão brasileira à China.

Obtida a concordância do governo chinês, no dia 4 de março de 1893, o governo brasileiro nomeou dois representantes, enviados extraordinários e ministros plenipotenciários para a Missão Especial, o Barão de Ladário, José da Costa Azevedo, e o Almirante da Marinha, o Sr. José Gurgel do Amaral Valente, que era Embaixador Brasileiro na Suíça. O chefe da Missão Especial, o Barão de Ladário partiu para o seu destino em 24 de abril de 1893, mas o segundo membro, o Sr. Valente, já nomeado como ministro à China, faleceu em Viena no seu cargo na Legação da Áustria-Hungria no início do junho, e José Azevedo recebeu esta mensagem quando já tinha chegado a Paris. Para o lugar deste foi nomeado em 28 de outubro o Dr. Joaquim Francisco de Assis Brasil, ministro à China. Enquanto esperava a chegada do novo embaixador brasileiro a China, o almirante negociou com Tching Tchang em Paris, sobre a questão da imigração.

Depois destas negociações em Paris, o Ministério das Relações Exteriores do Brasil recebeu a mensagem de José Azevedo, o Barão de Ladário, na qual ele expressou que podia "garantir desde agora o bom êxito da Missão Espacial Brasileira enviada ao meu país"4. E ao Tsung-Li Yamên, foi entregue pelo Xue Fucheng, um telégrafo, reportando que "chegamos um acordo em geral, e as discussões detalhadas ficariam com menos dificuldades." As duas partes, chinesas e brasileiras, estavam confiantes sobre o sucesso da Missão quando esta partiria de Paris para Pequim. No entanto, no presente artigo encontra-se, por meio da comparação das interpretações diferentes entre diplomatas brasileiros e chineses sobre os itens acordados e os acontecimentos posteriores, divergências estas que prejudicariam as reações futuras à chegada da Missão na China.

\section{A primeira rodada de negociações entre Gabriel Piza e Tching Tchang e os acordos}

4 AZEVEDO, 1893, p.95.

${ }^{5}$ CHEN, 1985, p. 1209. 


\section{alcançados}

O pedido do Brasil para o envio de uma missão foi aprovado com muita tranquilidade, especialmente quando comparado com as dificuldades encontradas pela primeira missão à China. Quando a Missão Especial de 1879 foi lançada a Pequim, Tsung-Li Yamên não tinha nenhum interesse nas iniciativas de migração, e declarou a Eduardo Callado e Arthur Silveira da Motta, Enviados Extraordinários e Ministros Plenipotenciários em Missão Especial na China de 1879 , que "não há nenhuma possibilidade para o recrutamento de trabalhadores chineses"6. No entanto, o crescimento populacional deu pressão à estabilidade social, e o movimento mundial de perseguição e exclusão a imigrantes chineses em nome do anti-slavery ocasionou a grande onda repatriada à China, o que gerou ainda mais problemas de estabilidade social. Ao mesmo tempo, a imagem de Brasil concretizou-se pelas duas investigações feitas respectivamente por Tong King-sing e Fu Yun-long, mostrando a sua grande área fértil com pouco povoamento ${ }^{7}$. A possibilidade de povoar no Brasil foi levada em consideração pelo governo de Qing $^{8}$ sob contínuos convites brasileiros à imigração chinesa. Nesse caso, quando a observação de Piza relativa à ideia de enviar uma missão à China foi transmitida para TsungLi Yamên, a permissão foi retornada em pouco tempo por Xue ${ }^{9}$.

No entanto, a atitude favorável do governo Qing não se mostrou a Gabriel Piza. A resposta de Li Hung-chang ${ }^{10}$ a Xue em 12 de novembro enfatizou que "a emissão de enviados especiais do Brasil tem que possuir certificado de credibilidade, que deve ser recebido de acordo com a etiqueta atual da China". No aspecto de recrutamento, Li exigiu que Xue "consulte a missão sobre suas intenções da chegada e não mencione o recrutamento de trabalhadores" ${ }^{11}$. Por isso,

6 ENCONTRO DA ANPUH DF, 2020, p.1007.

7 ENCONTRO DA ANPUH DF, 2020, p.1014.

8 A dinastia Qing (Chinês: 清朝; Pinyin: qīng cháo; Wade-Giles: ch'ing ch'ao), foi a última dinastia imperial da China, governando por 268 anos (de 1644-1912) com uma breve restauração fracassada em 1917.

9 Tsung-Li Yamên, 01-15-047-06-006.

10 Li Hung-chang (Chinês: 李鸿章;Pinyin: Li Hongzhang; Wade Giles: Li Hung-chang) (1823 -1901), Marquês de Suyi. Foi político e diplomata chinês do final da dinastia Qing. Ele serviu em posições importantes na corte imperial Qing, incluindo serviços ao vice-rei de Zhili, Huguang e Liangguang. E liderou os negócios ao exterior da China em Tsung-Li Yamên.

11 LI, 2007, p. 502. 
Xue enviou a observação a Gabriel de T. P. de Almeida, informando que a missão “terá recepção segundo a etiqueta chinesa atual, igual aos enviados de outros países, para mostrar a amizade", e consultando as informações dos enviados para que pudessem tirar as documentações necessárias à entrada no país como a agenda de viagem, títulos e nomes dos enviados, não mencionando nada sobre o recrutamento ${ }^{12}$.

Na verdade, o conservadorismo do lado chinês quanto à questão da emigração ao Brasil pode ter sido uma estratégia de negociação adotada para proteger a segurança das vidas e bens chineses, conforme os telegramas enviados de Xue ao Tsung-Li Yamên em 26 de janeiro de 1893, nos quais ele diz: “- Para a solicitação do Brasil, será melhor recusar primeiro.

— Com solicitações repetidas, a negociação do bem-estar de emigrantes poderia ganhar mais benefício, quando garantir o estabelecimento e a validade de cláusulas específicas para o direito da proteção consular ${ }^{13}$." Em 22 de fevereiro de 1893, depois da conversa entre Tching e Gabriel de T. P. de Almeida, Xue também informou que "devemos esperar que eles implorem repetidamente para que criem capítulos especiais, e adicionamos consulados, assim podemos ter um certo controle da situação"14 para alcançar o benefício ao povo chinês e a autonomia do governo.

$\mathrm{Na}$ época, Xue estava em Londres, e mandou Tching Tchang, conselheiro baseado em Paris, negociar com Gabriel Piza. Quanto às intenções da missão, Tching também remeteu uma atitude negativa, dizendo que “- Há muitos poucos negócios entre a China e o Brasil e não há contatos frequentes entre cidadãos. - Caso envie funcionários para estabelecer agência em Pequim, não teria muitos assuntos" ${ }^{15}$. Gabriel Piza contestou:

- O propósito de enviados do nosso país é, primeiro, para manter a amizade; e o recrutamento, em segundo lugar; comércios em terceiro. - Desde o estabelecimento da democracia, temos feito grandes esforços para governar e rejuvenescer o país, principalmente em favor da terra e do foco nos negócios. - O Brasil é um país com um vasto território, somente menor que o dos

12 TSUNG-LI YAMÊN, 01-15-047-06-006.

13 TSUNG-LI YAMÊN, 2020, 01-15-047-06-007.

14 CHEN, 1985, p. 1208.

15 TSUNG-LI YAMÊN, 2020, 01-15-047-06-006. 
Estados Unidos, rico em solo e escasso em povoamento. - Há de dois a três milhões de imigrantes ocidentais por ano. - No entanto, ainda estamos sofrendo um problema de pouca população, razão pela qual procuramos o recrutamento de chineses. - Se o povo chinês puder vir, isso será benéfico para os dois países. ${ }^{16}$

A resposta de Piza esclareceu diretamente o motivo essencial do recrutamento de chineses para trabalhar no Brasil, e argumentou as vantagens da imigração, tais como área larga disponível, tradição amigável à imigração e a grande demanda de trabalhadores. O mais importante é que o Brasil teve alguma compreensão dos problemas populacionais que a China enfrentava ${ }^{17}$, embora o governo asiático não tivesse mostrado uma atitude positiva. Quando Callado foi a Pequim em 1879, ele recebeu uma clara rejeição do governo chinês sobre o recrutamento, de modo que só poderia usar o estabelecimento de relações diplomáticas para alegar que não tinha propósito de imigração. Foi somente após a investigação de Fu Yun-long sobre o Brasil em 1889 que a parte Qing esclareceu o propósito da missão à China em $1879^{18}$. Mas, desta vez, o Brasil também expressou seus desejos de forma mais explícita, demonstrando que também viram a atitude abrandada do governo Qing acerca dessa questão. Ou seja, em comparação com o contexto de 1879 , agora as duas partes se conheciam e entendiam melhor os benefícios da migração de cada um, estando ambos com vontade de estabelecer uma iniciativa migratória entre si, o que também foi confirmado na resposta de Tching a Gabriel Piza, na qual afirma que "já procurávamos anteriormente um benefício mútuo na emigração"19.

Enquanto isso, Tching destacou na conversa uma preocupação fundamental do governo Qing, a questão da proteção dos imigrantes chineses. Pois "no passado, os trabalhadores chineses foram abusados repetidamente, e hoje há uma dificuldade para o governo permitir isso."

\footnotetext{
16 TSUNG-LI YAMÊN, 2020, 01-15-047-06-006.

17 Nas conversas entre Gabriel e Tching, o ministro em Paris disse que "Atualmente a Grã-Bretanha e suas colônias seguem a proibição de trabalhadores chineses nos Estados Unidos, o que vem obstaculizando a sobrevivência de chineses. A autorização de chineses trabalharem na lavoura brasileira seria um método criativo, que beneficiará a resolução dos dilemas que eles estão enfrentando. Acredito que Tsung-Li Yamên também considerará isso" (TSUNG-LI YAMÊN, 2020, 01-15-047-06-007).

18 ENCONTRO DA ANPUH DF, 2020, p.1009.

19 TSUNG-LI YAMÊN, 2020, 01-15-047-06-006.
} 
E indicou que "se não houver medidas efetivas e confiáveis para prevenir os abusos, as solicitações dificilmente serão autorizadas, com a nossa determinação de proteger o povo"20.

Neste ponto, emergiu uma ameaça potencial à cooperação sino-brasileira acerca da migração, sendo ela os planos divergentes sobre a forma de migração. Os imigrantes chineses que o Brasil procurava com o intuito de preencher a ausência de mão-de-obra na lavoura desde a abolição de escravatura eram os de baixa remuneração e com alta obediência, como os que tinham trabalhado nas colônias espanholas e que tinham gerado grande lucro aos proprietários de plantações em Peru e Cuba, ou, mais especificamente, vinham a América por cadeia de coolies. Mas o tal caminho de "migração" estava cheio de fraudes e tráfico humano no recrutamento, grande taxa de mortalidade por falta de condição mínima de sobrevivência durante o transporte e abusos e massacres no destino. Além disso, o tráfico de coolies prosperava especialmente em Macau, colonizado por Portugal, o que significou um controle vulnerável da corte Qing.

Por isso, ao invés de permitir que as empresas brasileiras contratassem trabalhadores na China via corretores macaenses, Xue propôs um plano de livre saída de chineses com consulado estabelecido no Brasil para proteger os direitos e interesses dos chineses que iam voluntariamente para o país; assim, podiam evitar o tráfico humano recorrente. Ou seja, como o controle verdadeiro de Hong Kong e Macau não pertencia à China naquela época, o governo Qing foi impotente nos recrutamentos ilegais. No processo de negociação com Brasil, a China buscou estabelecer um meio de emigração diferente daquela do passado, com base na igualdade entre os dois países, via cooperação governamental, obtendo então certa iniciativa neste assunto $^{21}$. Isso foi exatamente o oposto do que o Brasil pensava: a missão obviamente esperava fazer referência ao sistema existente de transporte e legalizar os recrutamentos anteriormente de status ilegal.

Diante da proposta chinesa sobre o assunto, Gabriel. de T. P. de Almeida respondeu que o Brasil ainda não tinha uma norma explícita para garantir o bem-estar dos chineses, mas ele

20 TSUNG-LI YAMÊN, 2020, 01-15-047-06-006.

${ }^{21}$ CHEN, 1985, p. 1208. 
poderia consultar a fim de entender o presente plano específico, e depois Tching poderia discutilo detalhadamente com ele ${ }^{22}$.

O retorno de Piza chegou sem demora, segundo a mesma observação entregue a Xue e telegrafada ao Tsung-Li Yamên, Piza permitiu a supervisão do governo chinês sobre os assuntos de emigração, e pediu a eles medidas específicas que pudessem ser autorizadas no Brasil, prometendo que chineses “deveriam ouvir a fiscalização e o cuidado dos funcionários chineses e, em seguida, retornariam por sua vontade com bem-estar. Podem determinar certos métodos da proteção, para que possam obter todos os direitos" ${ }^{23}$. Em relação à sua consulta dos regulamentos específicos, Tching explicou que "não podemos oferecer um plano determinado. Necessitamos ainda a decisão tomada pelo Tsung-Li Yamên depois de análise, o que pode ser difícil de prever agora no exterior". Entretanto, ele apresentou uma resenha de regulamentos, por tom pessoal,

Caso seja possível organizar o recrutamento pelo governo chinês, com medidas preventivas aos maus costumes antigos, ou supervisar sob as autoridades chinesas. Se quiser evitar o regulamento chinês e lançar recrutamentos sem permissão, a autorização da emigração chinesa ao Brasil enfrentará dificuldades para ser deferida. ${ }^{24}$

Até então, Tching já havia explicado a linha de fundo do governo chinês acerca do assunto, ou seja, que seria proibido recrutar chineses da forma feita anteriormente, através de corretores privados sem permissão legal. Além disso, ele esperava que a negociação de regulamentos específicos pudesse ser realizada quando a Missão chegasse a Pequim. Sobre os regulamentos específicos, Piza não concordou diretamente, e pediu ao Tching que considerasse a proposta do Brasil $^{25}$.

"Obtido o acordo do Governo da China"26, os Srs. Almirante José da Costa Azevedo e

22 TSUNG-LI YAMÊN, 2020, 01-15-047-06-006.

23 TSUNG-LI YAMÊN, 2020, 01-15-047-07-007

${ }^{24}$ TSUNG-LI YAMÊN, 2020, 01-15-047-07-007

25 TSUNG-LI YAMÊN, 2020, 01-15-047-07-007.

${ }^{26}$ BRASIL, 1894. 
José Gurgel do Amaral Valente foram nomeados enviados extraordinários e ministros plenipotenciários em missão especial. Assim iniciava-se o despacho da Missão.

Baseando-se em todos os resultados de negociações entre Gabriel Piza e Tching Tchang, Xue resumiu ao Tsung-Li Yamên:

\begin{abstract}
Verifica-se que enviados de missões estrangeiras contém geralmente um líder no país. Desta vez, o Brasil pretende enviar os dois, um especificamente para discutir assuntos de recrutamento. O Brasil está com terra vasta e pouco povoada, tomando a procura de mão de obra como tarefa urgente. A chave de recrutamento é o controle adequado sob nossas autoridades, cabendo a elas controlar a aprovação e proibição, o que deve ser discutido e esclarecido com os brasileiros, evitando os costumes de abuso na forma anterior. Assim, estabelecer consulado chinês no Brasil, determinando os regulamentos na proteção $0^{27}$.
\end{abstract}

Em 22 de fevereiro de 1893, depois da conversa entre Tching e Gabriel de T. P. de Almeida, Xue também informou que "- Hoje, se quisermos beneficiar nosso povo, devemos permitir sua solicitação da emigração chinesa ao Brasil, e proteger a autonomia do nosso governo, assim evitamos que os expulsem no futuro." 28 Esta mensagem tornou-se o princípio chinês em toda negociação, isto é: 1) Concordância na migração; 2) Insistência no direito de supervisão chinesa no processo de recrutamento e 3) Evitar abusos de trabalhadores como antes.

Nesta fase, o governo Qing já possuía uma posição mais clara diante da cooperação migratória. A partir do ponto de vista chinês, havia um interesse muito claro no tema, e também se entendia o efeito positivo da emigração ao Brasil, para o alívio da pressão sobre a população nacional; por outro lado, os dolorosos resultados, em vista dos crimes de discriminação enfrentados pelos emigrantes chineses no passado, especialmente aqueles na tendência da cooperação migratória com americanos, fez com que o governo Qing colocasse a proteção dos trabalhadores em primeiro lugar.

27 LI, 2007, p. 2113. Vê-se também em: TSUNG-LI YAMÊN, 2020, 01-15-047-07-007.

28 CHEN, 1985, p. 1208. 
Ao mesmo tempo, o governo chinês também concebeu uma proposta específica na proteção, com ênfase particular no direito organizacional do governo chinês sobre o recrutamento - por exemplo, exigir o recrutamento sob a supervisão de instituições chinesas relevantes e criar um consulado no Brasil para que os interesses dos imigrantes chineses pudessem ser garantidos no exterior. Em outras palavras, antes os estrangeiros que tinham recrutado trabalhadores na China baseavam-se geralmente nas companhias de livre comércio, enquanto os trabalhadores eram reduzidos a commodities durante este processo. Longe disso, a potência asiática queria estabelecer um novo meio de emigração, ou seja, a cooperação a nível governamental com o Brasil, limitando os direitos de emigração como trabalhadores aos consulados chineses e brasileiros. Tal proposta foi discutida nas conversas entre Tching e J. da C. Azevedo posteriormente.

Em resumo, as visitas precedidas de Eduardo Callado e Arthur Motta (1879-1882), Tong King-sing (1883), e Fu Yun-long (1889) estabeleceram uma base de conhecimento entre China e Brasil, permitindo que ficassem claras para ambas as partes sobre as necessidades de migração no ano de 1893. O motivo da Missão de 1893 foi muito explicito, e a imigração chinesa no Brasil foi uma política que beneficiaria os dois países, confirmado e concordado por oficiais chineses e brasileiros durante as negociações em Paris antes que a nova Missão chegasse. $\mathrm{O}$ segundo princípio, que Gabriel Piza e Tching Tchang atingiram, era a proteção aos imigrantes chineses em geral, incluindo o recrutamento sob supervisão de autoridades chinesas, e o estabelecimento de consulados no Brasil, apesar de não ter sido esclarecida pela parte brasileira a permissão às propostas especificas de proteção, especialmente nos aspectos das formas de recrutamento e dos meios de transporte. Com uma base do consenso geral, só esperavam a chegada da Missão à Pequim para discutir detalhes do recrutamento.

\section{A segunda rodada de negociações entre José Azevedo e Tching Tchang, e a divergência nas interpretações do memorandum}


Enquanto o plano era discutido entre Piza e Tching, a Missão não partiu para Pequim logo após uma curta estadia em Paris. Segundo o relatório confiado à direção do Barão de Ladário, Azevedo chegou a Paris primeiro e lá esperou por José Gurgel do Amaral Valente, outro ministro plenipotenciário, que até então estava em Viena. Foi adiada a realização da entrevista com Tching Tchang, a qual tinha sido intermediada por G. de T. P. e Almeida, "afim de que a ele assistisse o meu colega da Missão, o Sr. Amaral Valente." 29 No entanto, "assim que o Barão de Ladário chegou a Paris, recebeu a notícia de que Valente havia falecido na Áustria." ${ }^{30}$ Ele enviou "um telegrama ao seu país, esperando até que os enviados novos a Paris chegassem ao destino, e então viajaria para a China."31

Portanto, J. da C. Azevedo realizou duas entrevistas com Tching Tchang em Paris nos dias 26 e 27 de junho, enquanto estavam esperando a chegada do novo ministro plenipotenciário da missão, colocando em evidência medidas detalhadas do recrutamento.

No início, o Barão de Ladário apresentou a Tching uma introdução geral da proposta brasileira, expressando primeiro que os chineses eram bem-vindos, especialmente para as províncias de Minas, Rio de Janeiro, São Paulo etc. Os imigrantes chineses poderiam trabalhar principalmente na agricultura, e mineração como opção alternativa, além de outros trabalhos. Ele enfatizou que eles poderiam levar parentes, esposas e filhos para viver junto com eles, além de apresentar que os trabalhadores brasileiros eram divididos em oficiais e civis:

Trabalhadores que contratam oficialmente recebem alimentos e salário pelo governo. Os que contratam com ricos proprietários são classificados como civis, recebem alimentos e salário do próprio proprietário. São eles contratados civis, que devem ser informados ao oficial para registro e verificação. ${ }^{32}$

A apresentação de Azevedo confirmou novamente o motivo brasileiro para a política

${ }^{29}$ AZEVEDO, p. 86.

30 TSUNG-LI YAMÊN, 2020, 01-15-047-07-007.

31 TSUNG-LI YAMÊN, 2020, 01-15-047-07-007.

32 CHEN, 1985, p. 1209-1211. 
promocional da imigração, que era preencher a demanda de trabalhos na lavoura. Com essa natureza, apesar do recrutamento brasileiro conter participação oficial, a maioria dos trabalhadores entrou no setor privado. De um lado, chineses eram reconhecidos como imigrantes, entrando no Brasil pela mesma forma do recrutamento de imigrantes ocidentais. Isso foi um avanço significante nesta Missão, especialmente em comparação com a anterior, na qual Henrique Carlos Ribeiro Lisboa, secretário de missão em 1879, aconselhava a “importação de trabalhadores chineses" com a vantagem de que eles sempre preferiam voltar à sua terra natal, e não eram "propriamente um povo colonizador, especialmente para os países em que predomina a raça europeia." ${ }^{33}$ Ou seja, chineses que tinham sido vistos como bens importados, jogados fora depois de usados, eram tratados no plano de Azevedo, pelo menos, como seres humanos sob a identidade de imigrantes. Além disso, Azevedo também sugeriu que os chineses pudessem imigrar com a família, permitindo o povoamento asiático no território brasileiro, igual aos imigrantes de outros países. Segundo a sua apresentação à Tching, a proposta brasileira diferenciava-se muito do tráfego de coolies, o que foi amplamente criticado por imprensas britânicas contra a Missão. De outro lado, o recrutamento de chineses atendia principalmente demandas de proprietários de grandes plantações, e então esses trabalhadores não possuíam condições de plantar em suas próprias terras ou acumular riquezas para se integrar ao local como cidadãos. Tal risco potencial na liberdade e igualdade seria mais evidente no recrutamento de imigrantes chineses.

No que diz respeito à forma de recrutamento, Azevedo apresentou que

O método geral é o mesmo tomado por países ocidentais. Propõe-se a criação de um consulado na China e a instalação de um navio-companhia para transporte de passageiros e mercadorias. Todos os chineses que desejam vir ao Brasil podem pedir permissão ao escritório consular. Se o solicitante for um bom cidadão, a licença será concedida e uma companhia relevante avançará para se hospedar no exterior. Assim que chegar ao Brasil, os imigrantes vão morar temporariamente em um escritório de recrutamento, dependendo da sua profissão, o que for apropriado, assinará contrato, seja como trabalhador oficial ou civil, conforme sua conveniência. O governo brasileiro pagará os

33 LISBOA, 2012, p. 310. 
créditos à companhia, caso imigrantes sejam contratados pelo governo. No caso de civis, os créditos serão devolvidos pelos proprietários que queiram contratá- $\operatorname{los}^{34}$.

De acordo com a citação acima, acredita-se que o governo republicano planejava transportar imigrantes chineses da mesma forma que fazia com os outros imigrantes ocidentais livres. Ou seja, o consulado que seria estabelecido na China após a Missão era responsável pela verificação das identidades dos solicitantes chineses, e companhias privadas ofereciam serviços de transporte, que eram pagos por quem recebia e contratava os imigrantes. No entanto, esta forma de recrutamento era semelhante ao recrutamento de trabalhadores sob contrato (Indentured labor), termo usado para descrever asiáticos de variadas culturas e origens (chineses, indianos ou pessoas de outras descendências) que trabalharam nas colônias europeias e britânicas ${ }^{35}$. Vale notar aqui que a especificação do termo direcionado a asiáticos foi um resultado dos movimentos anti-slavery. As tragédias de coolies na época da escravatura se mantiveram, na maioria dos casos, sob contratos assinados com chineses nominalmente livres. Empresas corretoras pagaram passagens e contrataram trabalhadores. Depois de chegar ao destino, o contrato foi transferido para proprietários de fábricas ou plantações. Esses trabalhadores "livres" precisavam trabalhar para pagar juros rolando com baixos salários, e assim perdiam sua liberdade em parar de $\operatorname{trabalhar}^{36}$. Desta maneira, elevou-se o foco principal da negociação: Como evitar a repetição de tragédias durante o recrutamento?

A proposta do Barão de Ladário era a confirmação das condições de viagens marítimas, que eram opostas às de Peru e Cuba, garantindo que

34 CHEN, 1985, p. 1210.

35 GALENSON, 1984, p. 23; NORTHRUP, 1995; VARMA, 2017.

36 No telegrama entregado pelo Xue Fu-cheng para Tsung-Li Yamên no dia 06 de janeiro do ano de Guangxu (equivalente ao dia 22 de fevereiro de 1893), dizendo que "veem-se os defeitos em recrutamento de trabalhadores pelos países americanos, como Cuba, Peru, etc.. Eram os estrangeiros arrecadando fundos, recrutando trabalhadores chineses na China, firmando contratos com eles, pagando tarifas de navios, e os vendendo para plantações como bens lucrativos. Quando o contrato atingir o vencimento, esses trabalhadores foram revendidos vezes e vezes sem fim. Assim permanece trabalhando cruelmente em uma terra estrangeira pelo resto da vida como se fosse gados." Citado de: CHEN, 1985, p. 1208. 
Nosso país tem leis muito rígidas sobre o transporte de pessoas. Qualquer companhia que transportar trabalhadores de viagens remotas deve ter uma licença consular. Somente os imigrantes que assinam presencialmente, e que estão dispostos a vir para o Brasil, podem entrar em um navio. E definimos que os gabinetes de cada navio terão vagas limitadas e uma farmácia de oficial médico montada para prevenir doenças. As companhias transportam dezenas de milhares de trabalhadores todos os anos, cuidando bem deles e não cometem abusos ${ }^{37}$.

Segundo a proposta dele, seria o consulado brasileiro na China que monitoraria o recrutamento e selecionaria companhias transportadoras. As etapas para realização do recrutamento eram bem explícitas: 1) Estabelecer um consulado brasileiro na China; 2) Recrutar chineses e gerar licença consular para o transporte de trabalhadores. Sua resposta também refletiu do lado a pressão enfrentada pela Missão, a opinião de muitos "que afirmam serem os chineses novos escravos importados. ${ }^{38}$ " Por isso ele enfatizou a natureza voluntária dos passageiros e a condição higiênica dos navios.

Baseado nas decisões feitas por Xue, que telegrafou ao Tsung-Li Yamên, Tching também esclareceu ao Barão de Ladário as principais preocupações do Império, que incluíam: 1) O recrutamento deve ser organizado por funcionários chineses, com o pré-requisito de que os respectivos colaboradores chineses tenham chegado ao Brasil, investigando as condições lá e estabelecendo o consulado; 2) Os trabalhadores chineses que chegarem ao Brasil devem ser recebidos no tratamento nacional ou no tratamento nacional mais favorável. ${ }^{39} \mathrm{Na}$ proposta chinesa, as etapas de realização da migração com a Missão eram de sequência variada: 1) Negociar e estabelecer regulamentos de recrutamento com a Missão brasileira em Pequim; 2) Enviar a Missão chinesa ao Brasil para investigação das situações locais; 3) Instalar um consulado chinês no Brasil; 4) Recrutar chineses e gerar licença consular via consulado brasileiro com a supervisão de funcionários chineses do local; 5) Verificar condições de

37 CHEN, 1985, p. 1216.

38 LISBOA, 2018, p.33.

39 CHEN, 1985, p. 1209-1216. 
sobrevivência dos imigrantes embarcando no território brasileiro na supervisão do consulado chinês no Brasil.

Em outras palavras, apesar das garantias brasileiras acerca da condição higiênica de viagem terem sido aceitas pelo Tching no aspecto das formas de transporte, Brasil e China propuseram dois planos de recrutamento em divergência. A maior diferença era na implementação do recrutamento, ou seja, se a emigração seria gerenciada pelo governo chinês, baseando-se no regulamento negociado em Pequim, e o consulado estabelecido no Brasil. O cronograma de atividades também se diferenciava muito. Enquanto a Missão preferia iniciar o recrutamento assim que chegasse a China, o governo chinês pretendia organizar as atividades em um ciclo mais longo. Na identidade dos chineses, ambas as partes reconheceram que eles eram imigrantes iguais aos ocidentais, e o governo chinês preferia que eles pudessem ganhar o tratamento de nações mais favorecidas.

Apesar de muitas divergências nas propostas, Azevedo forneceu a Tching um memorandum assinado antes de partir para a China, no qual enfatizou quatro princípios fundamentais sobre o assunto: 1) O Brasil iria publicar em seu Jornal Oficial as decisões acordadas e proibir recrutamentos ilegais realizados por corretores ou companhias, antes que ele chegasse a Pequim, com regulamentos negociados como base de atividades; 2) A comercialização de transporte só se faria possível quando os enviados chineses ao Brasil confirmassem as condições do local, com consulados chineses no Brasil, e sob a supervisão de oficiais chineses. O público-alvo de contratação deve ser chinês no interior, evitando corretores ilegais em Macau e outras áreas litorais; 3) O método de recrutamento alcançado atende basicamente aos requisitos e sugestões apresentadas pela China, especialmente no que diz respeito à gestão de funcionários chineses, pelo governo chinês nas etapas de recrutamento e 4) As críticas e pressões de representantes europeus não prejudicaria atividades da Missão ${ }^{40}$. No entanto, após a leitura dos telegramas enviados aos respectivos países, as interpretações do mesmo documento variam consideravelmente.

De acordo com o telegrama que Azevedo enviou no dia 1 de julho de 1893, este 
memorando foi uma estratégia de negociação. Ele esperava que, ao concordar com o plano de Qing, promovesse a eficácia das negociações e acelerasse a missão à China. Pois Tching "reiterou com insistência o seu pedido", e Azevedo "tive com ele duas entrevistas das quais ele pediu me um memorandum". Ele explicou que "anuí ao pedido insistente do Encarregado dos Negócios da China, unicamente pelo motivo por ele alegado, de facilitar as primeiras negociações." 41 Ou seja o Barão de Ladário na verdade não concordou com o plano de recrutamento da China. Ele assinou o memorando apenas com o intuito de continuar a negociação diante da insistência chinesa. No entanto, o ministro poderia ter subestimado a disposição chinesa em cooperar na migração, pois esta atitude foi aplicada como uma estratégia pelos oficiais asiáticos.

No entanto, considerando os compromissos assumidos por José Azevedo, para os chineses esse memorando equivale à confirmação e concordância do Brasil com a proposta feita. Depois que a missão chegasse a Pequim, eles só precisariam determinar regulamentos específicos com base nos resultados das discussões em Paris. E então a próxima etapa poderia ser realizada, sendo ela, de acordo com este esquema, o envio de uma missão chinesa ao Brasil para verificar condições de trabalho, estabelecer o consulado, e então as atividades seriam supervisionadas por oficiais chineses. Assim começaria o recrutamento de chineses para o Brasil. Li Hung-chang até pediu para Fu Yun-long, que investigava o Brasil em 1889 e apoiava a migração, elaborar um regulamento específico sobre os procedimentos de recrutamento que poderia ser negociado e confirmado em Pequim ${ }^{42}$.

Assim, percebe-se um risco oculto e grave no futuro destino da Missão: a crise de confiança. Em julho de 1893, o navio Tetartos procurava trabalhadores chineses em Macau para vir ao Brasil antes que a Missão chegasse a Pequim ${ }^{43}$, quebrando quase todos os princípios enfatizados no memorando. Além disso, a explicação de Azevedo sobre a condição marítima transferiu uma informação importante para Tching, a relação entre companhias transportadoras e o governo brasileiro. Portanto, no caso em que o navio Tetartos chegou a Macau em nome da

${ }^{41}$ AZEVEDO, 1893, p. 86.

${ }^{42}$ LI, 2007, p. 388.

${ }^{43}$ CHEN, 1985, p. 1225-p. 1236. 
Companhia Metropolitana do Rio de Janeiro para o recrutamento de trabalhadores ao Brasil quando ainda não havia se chegado a um acordo entre China e Brasil acerca da imigração, o governo Qing tinha razões para duvidar da relação entre o recrutamento de Tetartos e o motivo da Missão em 1893, questionando se o Brasil poderia realmente cumprir com as garantias feitas durante as negociações de Paris.

\section{Conclusão: as influências indispensáveis das negociações em Paris para a Missão Especial à China em 1893}

Portanto, as duas rodadas de negociações em Paris foram importantes, visto que influenciou em várias vertentes o destino da Missão à China em 1893.

Antes de tudo, a Missão só se fez possível através das negociações entre Piza e Tching, nas quais combinaram o despacho de uma missão brasileira à China. Durante as negociações, Piza e Tching esclareceram o motivo específico da expedição, isto é, o recrutamento de trabalhadores chineses ao Brasil. Os dois diplomáticos também concordaram que imigrar chineses ao Brasil era um plano que beneficiaria interesses de ambos os países, o que foi base fundamental de todas as atividades diplomáticas posteriores.

Segundo, as negociações em Paris fizeram com que as duas partes entendessem as preocupações principais um do outro, e também as principais divergências, dentre quais se destacava a forma de recrutamento. Enquanto ambos se comprometiam em garantir o bem-estar dos trabalhadores recrutados, eles tinham propostas distintas acerca da forma de proteção. Para o governo brasileiro, a forma comum de imigrar estrangeiros era o recrutamento através de companhias autorizadas pelo consulado brasileiro, tal qual tinham feito com os europeus. Já para o governo chinês, eram necessárias a supervisão chinesa no recrutamento e a instalação do consulado no Rio de Janeiro.

Terceiro, demonstravam-se pelas fontes aplicadas neste artigo que o plano republicano tratava chineses como imigrantes no Brasil na Missão de 1893, diferenciando-se do tráfego de 
coolies, que foi amplamente criticada pelas imprensas inglesas da época. O Brasil preferia recrutar trabalhadores chineses com famílias, promovendo o povoamento e a integração chinesa ao território tropical. O Barão de Ladário também se comprometeu com a existência da igualdade entre imigrantes chineses e europeus nos aspectos do recrutamento e das condições de viagens marítimas. Tanto o Brasil quanto a China sofreram falsas acusações sobre o assunto da imigração chinesa ao Brasil em 1893.

No entanto, apesar dos acordos realizados, mostraram-se vestígios de falha da Missão devido às negociações em Paris.

Desde o ano de 1879, quando foi enviada oficialmente a iniciativa de recrutar chineses, sempre foi o Brasil que solicitava ao governo Qing a realização de tal plano. Durante as negociações em Paris, a parte chinesa manifestava em todo o processo a atitude cética acerca do assunto, a despeito de ser a estratégia de negociação. Por isso, o desempenho ativo brasileiro e o passivo chinês durante as negociações levavam avaliações errôneas sobre as vontades do outro. Enquanto os oficiais chineses preparavam regulamentos mais restritos para a negociação em Pequim com base na vontade forte do brasileiro, José da Costa de Azevedo, o verdadeiro responsável da Missão, subestimou a disposição chinesa em cooperar na imigração, e sentiu a pressão internacional, o que poderia ser uma das razões pelas quais ele decidiu desistir de ir a Pequim mais tarde.

Além disso, revelavam-se as propostas de recrutamento, especificando os meios a fim de evitar a repetição de coolies na segunda rodada de negociações realizadas em Paris por José Azevedo e Tching Tchang. No entanto, as interpretações variadas ao memorando assinado em Paris ofereceram um risco grave ao futuro destino da Missão, ocasionando uma grande crise de confiança quando o navio Tetartos chegou a Macau e quebrou todos os princípios acordados no memorando. 


\section{ANEXO: Ordem cronológica dos acontecimentos}

$05 / 10 / 1892$

A lei $n^{0} 97$ permitiu a livre entrada de chineses ao Brasil.

$25 / 10 / 1892$

Gabriel de Toledo Piza e Almeida enviaram a observação a Xue Fu-cheng, iniciando a Missão Especial à China.

$06 / 02 / 1893$

Gabriel de Toledo Piza e Tching Tchang negociaram sobre a proposta de migração.

$04 / 03 / 1893$

Os Srs. Almirante José da Costa Azevedo e José Gurgel do Amaral Valente foram nomeados enviados extraordinários e ministros plenipotenciários em missão especial.

$24 / 04 / 1893$

José da Costa Azevedo partiu para Paris.

$03 / 06 / 1893$

José Gurgel do Amaral Valente faleceu em Viena no seu cargo na Legação da Áustria-Hungria.

$27 / 06 / 1893-28 / 06 / 1893$

José da Costa Azevedo e Tching Tchang realizaram dois encontros em Paris.

$18 / 08 / 1893$

Gabriel Piza observou a Xue que o Dr. Joaquim Francisco de Assis Brazil deveria preencher a vaga de José Valente. 
$28 / 10 / 1893$

Dr. Joaquim Francisco de Assis Brazil partiu de Buenos-Aires à missão especial.

\section{Referências Bibliográficas}

AZEVEDO, José da Costa. China, Missão especial do Celeste Império, confiada a direção do Barão de Ladário. Rio de Janeiro: Biblioteca Nacional, 1893. Manuscrito. Disponível em: <http://objdigital.bn.br/objdigital2/acervo_digital/div_manuscritos/mss1452516/mss1452516. html>. Acesso em: 3 de junho de 2021.

BRASIL. Congresso. Câmara dos Deputados. Constituição (1894). Decreto no 1896, de 23 de novembro de 1894. Coleção de Leis do Brasil - 1894. Capital Federal. Disponível em: $<$ https://www2.camara.leg.br/legin/fed/decret/1824-1899/decreto-1896-23-novembro-1894540803-publicacaooriginal-42065-pe.html>. Acesso em: 2 de fevereiro de 2020.

BRASIL. Lei $\mathrm{n}^{\circ}$ 97, de 5 de outubro de 1892. Rio de Janeiro, 31 dez. 1892. v. 001, p. 104. Disponível em: < https://legis.senado.leg.br/norma/541047/publicacao/15713170>. Acesso em: 10 nov. 2019.

CHEN, Hansheng. Collection of Historical Documents Concern in Emigration of Chinese Laborers. 2. ed. Pequim: Zhonghua Book Company, 1985. 1 v. (3). Título em chinês:《华工出 国史料编》.

GALENSON, David W.. The Rise and Fall of Indentured Servitude in the Americas: an economic analysis. Journal of Economic History. New York, p. 1-26. mar. 1984. Disponível em: $<$ www.jstor.org/stable/2120553>. Acesso em: 3 de novembro de 2019. 
LI, Hung-chang. Obras Completas de Li Hung-chang. An Hui: An Hui Education, 2007. Título em chinês:《李鸿章全集》.

LISBOA, Henrique Carlos Ribeiro. A China e os Chins - Recordações de Viagem. Rio de Janeiro: Funag, 2012.

LISBOA, Henrique Carlos Ribeiro. Os Chins do Tetartos. Rio de Janeiro: FUNAG, 2018.

NORTHRUP, David. Indentured Labor in the Age of Imperialism: 1834-1922 (studies in comparative world history). Cambridge: Cambridge University Press, 1995. ISBN-13: 9780521485197.

TSUNG-LI YAMÊN. Portal of the Archives of the Institute of Modern History Online Database. Disponível em:

$<$ http://archdtsu.mh.sinica.edu.tw/filekmc/ttsfile3?@1:1883459517:0:>. Acesso em: 3 de junho de 2020.

VARMA, Nitin. Contracts, Contractors and Coolies. In: VARMA, Nitin. Coolies of Capitalism: assam tea and the making of coolie labour. Berlin/Boston: Gruyter, 2017. Cap. 2. p. 43-104. Disponível em: <https://www.jstor.org/stable/j.ctvbkjv0z.5>. Acesso em: 5 dezembro de 2015.

WANG, Jinxu. Um Estudo Comparativo: A Negociação da Imigração Chinesa ao Brasil (18791889). In: ENCONTRO DA ANPUH-DF, 9., 2020, Distrito Federal. ENCONTRO DA ANPUHDF. Distrito Federal: Universidade de Brasília-Unb, 2020. p.1007-1017. 